\title{
Subculturas e cibercultura(s): para uma genealogia das identidades de um campo*
}

\section{RESUMO}

O presente trabalho propõe uma genealogia dos conceitos de subcultura enquanto um dos elementos e mitos fundadores da cibercultura. Nosso objetivo é mapear as relações quase indistintas entre os processos de comunicação e sociabilidade de ordem subcultural, que já estavam presentes na constituição da cibercultura, a partir das diferentes contraculturas que a formataram (como os hackers, os cientistas, os ativistas, entre outros); e em suas atualizações e reconfigurações até sua disseminação a partir da potencialização das tecnologias de comunicação, especialmente na fragmentação dos inúmeros nichos e práticas sociais na Web.

\section{PALAVRAS-CHAVE}

cibercultura

subcultures

sociabilidade

\section{ABSTRACT}

This paper presents a genealogy of subculture's concepts as one of the key elements and "foundational" myths of cyberculture. Our main goal is to map the almost indistinctive relations between communicational and sociability processes of subcultural order that were already in the constituition of cybercultural as contemporary phenomenon from the different countercultures that have formatted them (such as hackers, scientists, artists, political activists, among others); and in its reconfigurations and actual elements from the dissemination of the communication technologies, speacially in its fragmented niches and social practices on the web.

\section{KEY WORDS}

cyberculture

information feudalism

commons

\section{Anacronismos ciberculturais}

O presente ensaio nasceu de uma inquietação teórica com vistas a uma problematização e breve historicização da emergência da cibercultura - ou, em um entendimento de vertente pluralista, "ciberculturas", dada a diversidade de definições e mesmo de interesses proporcionados pelos efeitos das tecnologias de comunicação e informação na sociedade contemporânea em relação às práticas e usos comunicacionais da Web e de outros artefatos tecnológicos.

Sublinhamos aqui algumas relações entre subculturas e contraculturas (Gelder \& Thornton, 1997, Muggleton \& Weinzierl, 2004, Goffman \& Joy, 2004, Canevacci, 2005) enquanto elementos essenciais das características desse campo transdisciplinar de estudos, a partir de sua gênese desde a segunda metade do século XX, com atenção a algumas de suas definições operatórias e exploratórias e fases históricas conforme apresentadas por autores como Macek (2005) e Turner (2006), bem como as inserções de objetos de análise comunicacionais e possíveis instrumentos para uma cartografia dos fenômenos tecnoculturais, já bastante discutidas por Felinto (2007) ao apontar a herança modernista da cibercultura.

A cibercultura é, nesse sentido, herdeira de diversas questões da modernidade. Elaborar uma cartografia da cibercultura significa também, portanto, desenhar linhas de tempo, paisagens temporais estranhas que conectam épocas distantes e se enraízam no secular projeto tecnológico do Ocidente.

(Felinto, 2007: 56)

A tentativa de refinamento do pensamento acerca dos fenômenos comunicacionais da cibercultura que permeia esse texto leva em consideração três fatores básicos: primeiramente a relação indissociável entre cultura e tecnologia, em um processo que vem em curso desde a modernidade; em segundo lugar, as intersecções homem-máquina em suas dimensões técnicas, sociais, antropológicas, econômicas, etc e; finalmente a representação de um imaginário advindo dessas tecnologias digitais nos produtos midiáticos como filmes, quadrinhos, publicidade, etc.

A tecnologia hoje é uma das metáforas mais potentes para compreender o tecido - redes e interfaces - de construção da subjetividade(...)

Os sujeitos com os quais vivemos, especialmente entre as novas gerações, percebem e assumem a relação social como uma experiência que passa fortemente pela sensibilidade (MARTINN-BARBERO, 2008: 20-21)

\author{
Professora do Programa de Pós-Graduação em Comunicação e Linguagens \\ da UTP/PR/BR \\ adriamaral@yahoo.com
}


Compreendemos que dessa perspectiva que intercala os contextos micro/macro nos quais a cibercultura é fundamentada, podem emergir possíveis metodologias de análise das estratégias e dinâmicas de construção das diferentes identidades e perfis online (Liu, 2007) sejam em comunidades digitais, sites de redes sociais, etc - e suas intersecções e mediações com o offline, questão que ainda "perturba" a área desde seus primeiros estudos, tanto no âmbito internacional quanto nacional.

$\mathrm{O}$ artigo visa compor um levantamento genealógico que delineia a própria identidade plural do campo, devido aos fatores de influência das subculturas por ele sofrida, e inicialmente incorporando subsídios celebratórios e críticos, nos quais ora ela é uma forma social equivalente à cultura contemporânea (Lemos, 2002) ora podendo "ser definida descritivamente como o conjunto de fenômenos de costumes que nasce à volta das novíssimas tecnologias de comunicação, da chamada informática da comunicação" (Rüdiger, 2008: 26).

Assim, através de alguns argumentos teóricos e exemplificações empíricas, observaremos ao longo do desenvolvimento do artigo as articulações entre as práticas sociais e usos de ferramentas de comunicação mediada por computador, que, por um lado elas ainda guardam elementos que indicam a emergência de uma miríade de subculturas e nichos culturais e mercadológicos (Anderson, 2006) - principalmente no que diz respeito aos usos orientados para os interesses como apontam os resultados da pesquisa sobre a juventude digital norteamericana, realizada pela Universidade de Berkeley (Kids' Informal Learning with Digital Media: An Ethnographic Investigation of Innovative Knowledge Cultures ${ }^{1}$, 2008). Em contrapartida, há uma manutenção de construção de outras formas de cultura de massa na própria rede (Recuero, 2008,) apontando para uma relação dialética entre online e offline e para processos de ruptura e de continuidades em em relação tanto ao conteúdo quanto à forma das mídias massivas.

Para compreendermos melhor essas formações subculturais e como elas se encontram no centro dos discursos e práticas da cibercultura, resgatemos o caráter mitológico da narrativa tecnológica e extrapolativa por excelência: a ficção-científica em seu subgênero cyberpunk.

\section{Ficções e utopias subculturais na fundação de um "novo futuro"}

Darryl, que também tem DNA de otaku², está convencido de que Taki não é membro desses Místicos, mas um personagem periférico de algum tipo - possivelmente, já que ele desenha games para um sistema telefônico japonês, uma das fontes de informações deles. Darryl diz que o nível mais elevado de jogo, para tecno-obsessivos, é sempre e puramente a própria informação, e ele acha que os Místicos podem ter focado no filme não como fãs, mas simplesmente pelo prazer de solucionar um quebra-cabeças que ninguém resolveu ainda. Ele postula uma célula de infoteóricos profissionais de alguma espécie, que são também, nesse sentido, otaku definitivo, infojunkies. Talvez empregados do braço de pesquisa e desenvolvimento de uma ou mais grandes corporações. (GIBSON, 2004, p. 199, grifos da autora)

O parágrafo acima, retirado do livro Reconhecimento de Padrões (Pattern Recognition) de William Gibson, apresenta um trecho de um email do personagem Parkaboy enviado à protagonista do romance, a coolhunter (caçadora de tendências) Cayce Pollard que investiga as origens e o autor das postagens de um "filme" na Web que virou um fenômeno de debates e apropriações entre os engajados em um determinado fórum de discussão a partir de suas inúmeras paródias e apropriações. Cayce foi contratada por Bigend, misterioso chefe de uma megacorporação de mídia, para localizar o paradeiro do autor original do filme e navega nas redes online e em viagens presenciais por Londres e Tóquio em uma arqueologia subcultural de um bem simbólico.

Para tanto, além de ser ela mesma uma observadora assídua do fórum, ainda conta com informantes que lhe repassam as mais atualizadas informações e contatos para desvendar o quebra-cabeça viral. Cayce é uma pseudo-netnógrafa da ficção que rastreia perfis online e detecta comportamentos de consumo e tendências de modas de subgrupos específicos que em breve serão cooptados pelo "mainstream".

O trecho do email, que descreve o perfil de um dos indivíduos envolvidos com o tal filme, pode soar um tanto excessivo para quem não convive com as linguagens, manias e comportamentos dos subgrupos de fãs ou geeks, mas no entanto, ele nos descreve um possível contexto micro e cotidiano nas redes e segmentações potencializados pelas tecnologias de informação e comunicação, e, mais especificamente pela Web. Ao descrever o personagem Taki em um email, Parkaboy (ou melhor, William Gibson) nos dá pistas para compreendermos o papel fundamental das formações, do capital subcultural (Thornton, 1996) e da negociação e experimentação das identidades de sujeitos online (Donath, 1999) desde os primórdios do que se considera cibercultura.

A escolha de Gibson para essa introdução não foi uma mera casualidade. Conforme discutimos anteriormente (2008), o conceito de ciberespaço como matrix surgiu de sua prosa ácida e cinematográfica que rompeu fronteiras entre o gueto da literatura de Ficção Científica e da literatura mainstream, em uma interface com as teorias literárias e culturalistas pós-modernas. Tendo cunhado o termo ciberespaço no hoje clássico romance cyberpunk Neuromancer (1984), o autor tem, desde então, narrado a potencialização de imaginários presentes-futuros-próximos ${ }^{3}$, a partir de sua visão de mundo noir, irônica e distópica, sintonizada em um canal morto, no qual humanos e máquinas se fundem em um ambiente de espetacularização midiática.

Em Neuromancer, o autor adaptou o linguajar e os 
trejeitos das subculturas de ruas, em especial da geração punk em seu niilismo retro-futurista para suas observações e descrições da sociedade contemporânea em uma ficção-científica que parte da efervescência de um período histórico que viu nascer a cultura da microinformáti$\mathrm{ca}$, desenvolvida tanto com base nos projetos colaborativos de cientistas, teóricos da cibernética e militares, quanto dos movimentos artísticos contraculturais, políticos e libertários, tão distintos entre si como a New Left, os New Communalists e a geração beatnik, entre outros.

Desses legados aparentemente contraditórios da "cultura da pesquisa militar-industrial, que apareceu primeiro durante a Segunda Guerra Mundial e floresceu através da era da guerra fria, e a da contracultura NorteAmericana" ${ }^{4}$ (Turner, 2006: 03) veremos o surgimento das primeiras redes de colaboração online (como as famosas listas de discussões WELL e Usenet) a partir da adoção por parte de ambos os lados "dos computadores e de uma nova retórica cibernética dos sistemas e da informação. Eles começaram a imaginar instituições como organismos vivos, redes sociais como teias de informação, e a busca e a interpretação das informações como chaves para a compreender não apenas os mundos técnicos como também os mundos naturais e sociais." ${ }^{5}$ (Turner, 2006, p.04).

Para além da ficção-científica, os próprios discursos e teorias da cibercultura (Benedikt, 1994, Dery, 1997, Dixon \& Cassidy, 1998, Tofts, 1998, Bell \& Kennedy, 2000, entre outros) que emergem nesse primeiro momento fazem eco às subculturas da era do computador conforme descreve Macek (2005), discutindo temas como a cultura hacker (Levy, 1984, Goffman \& Joy, 2004), os ciberativistas (Barbrook \& Cameron, 2001), os digerati (Brockman, 1996), e os primeiros usuários das então chamadas comunidades virtuais (Rheingold, 1993)

Já em Reconhecimento de Padrões, escrito 20 anos depois de Neuromancer, o cenário do futuro próximo cede lugar a um presente no qual os hábitos de consumo são interpelados pelas redes digitais e as relações de sociabilidade se constituem a partir de fragmentos da cultura de massa, dispersa em fóruns, blogs e sites de redes sociais ao alcance de fãs/grupos que investem seu tempo e capital social em uma busca frenética por informações.

Nessa passagem de duas décadas, a noção de ciberespaço como "alucinação consensual" proposta por Gibson soa como datada, uma vez que há uma relação de contigüidade entre o online e o offline, no qual "o virtual e o real não são dois mundos paralelos: existem em relação dialética, o que significa dizer que entretêm relações de complementaridade, dependência recíproca e dinâmica tempestuosa". (Rüdiger, 2008: 23). O próprio Gibson, em entrevista recente, revela essas mudanças em termos de produção, disseminação, armazenamento e recuperação das informações (Ross, 2001).

Eu queria uma maneira de visualizar a extensão à qual algo mudou desde que comecei a escrever so- bre tecnologia da informação. Quando eu cunhei a palavra ciberespaço, o ciberespaço estava lá, e todo o resto estava aqui. Aquilo foi revertido ao longo do curso da minha escrita. Eu penso literalmente que o ciberespaço está aqui agora, e uma completa falta de conectividade está lá agora. Se nós pudéssemos ver as trocas sem fio da informação digital tomando o seu lugar ao nosso redor, n's estaríamos vivendo em uma paisagem visual muito mais poluída. A maior parte do que nós fazemos enquanto sociedade, nós agora fazemos basicamente de forma digital, no que costumávamos chamar de ciberespaço, ou nós fazemos simultaneamente digitalmente e no mundo físico. Se você estiver dirigindo com um sistema de GPS, você está simultaneamente dirigindo seu carro e manobrando o carro através de um constructo digital. Acredito que muito poucos de nós estão alertas para a extensão do que já aconteceu, e suspeito que eu não estou nem perto de estar alerta da rela extensão do que aconteceu. (Gibson, 2008: Online) ${ }^{6}$

\section{0 papel das subculturas na produção e distribuição de conteúdo online}

Com tantas mudanças e amplificação de acesso à cultura digital nas últimos anos, o papel das subculturas em relação às tecnologias digitais também se alterou. Seus membros dos primeiros tempos de BBS, listas de discussão, etc, definidos por Jenkins (2006) como fãs early-adopters - aqueles que adotam antes uma determinada tecnologia - também sofreram mudanças culturais significativas.

Jenkins (2006: 06) defende que no contexto das tecnologias de comunicação, a cultura do fandom $^{7}$ (o coletivo dos fãs, em uma tradução livre) tanto foi reformatada quanto ajudou a reformatar a cibercultura, produzindo uma diversidade de tipos de conhecimento diferentes em nossos ambientes midiáticos. O contexto histórico do nascimento da Internet e da cibercultura em si, já deixavam esses usos bem explícitos, a partir das relações estreitas entre os fãs-leitores de ficção-científica e os usuários das primeiras tecnologias (Jenkins \& Tulloch, 1995).

Fãs adotaram antecipadamente as tecnologias digitais. Dentro das instituições militares ou científicas onde a Internet foi primeiramente introduzida, ficção científica tem sido a literatura preferida há muito tempo. Conseqüentemente, as gírias e práticas sociais empregadas nos primeiros boletins eletrôni$\cos$ (BBS) eram quase sempre diretamente modeladas pelo fandom de ficção científica. Listas de discussão cujo foco em tópicos de fãs tinham seu lugar juntamente com discussões de assuntos tecnológicos ou científicos." (Jenkins, 2006: 138) ${ }^{8}$

Não pretendemos aqui traçar um histórico conceitual do termo subcultura, suas origens e problematizações ${ }^{9}$ desde a Escola de Chicago, passando pela Escola de 
Birmigham e finalmente aos estudos pós-subculturais a partir dos anos 90 do século passado. No entanto, cabe fazer um breve desvio e abordar a problemática levantada por Canevacci (2005), que leva em consideração as apropriações ${ }^{10}$ dos jovens em relação a essas culturas.

Como lembra Burke (2003: 115),

é difícil, se não impossível, dizer como o processo funciona e a que ponto a cristalização e a reconfiguração são inconscientes e coletivas e até que ponto dependem de indivíduos criativos. Mesmo assim, este aspecto da troca cultural certamente merece ser enfatizado, quer estejamos pensando no passado, no presente ou no futuro.

Também nos parece fundamental trazer para a discussão a noção de Canevacci (2005) de culturas intermináveis, ancoradas no consumo midiático e no prolongamento constante da juventude enquanto possibilidade de experimentação identitária, seja através das tecnologias digitais ou de fenômenos como as modificações corporais, cirurgias estéticas, moda, etc.

Nesse sentido, a própria cibercultura, ou ciberculturas, se pensarmos em sua multiplexidade de mídias ${ }^{11}$ (Haythornthwaite, 2005) seria uma cultura interminável ao gerar processos de obsolescência e nascimentos a todo instante. Para o autor, a morte das contraculturas de caráter ideológico - dos anos 60 acontece justamente no período de ascensão das subculturas

A expressão "contracultura" nasce pelo final dos anos 1960 e morre no início dos 1980 . O prefixo "contra" atestava a dimensão da oposição que as novas culturas juvenis dirigiam à cultura dominante ou hegemônica. Ser contra significava que, antes de qualquer possibilidade de falar em cultura, aliás, ainda antes de chegar ao termo "cultura" era preciso ser antagonista, opositor. (Canevacci, 2005: 13)

Segundo o antropólogo, "uma subcultura não é, por sua natureza, uma contracultura, porque pode ser também uma cultura pacificada, organizada, mística, etc." (Canevacci, 2005: 19), contudo, segundo ele, tais distinções embora importantes não dão conta dos "pluriversos" que se tornaram as culturas juvenis.

No entanto, observamos que a idéia de subcultura vinculada a um caráter nacional e cujo "prefixo "sub" indica mais um conceito que aspira a uma maior neutralidade científica" (Canevacci, 2005: 19) desconsidera ainda o redesenho que o termo começa a ganhar a partir dos estudos pós-subculturais, quando os teóricos justamente deixam de lado a questão do nacional e do caráter de resistência a ele associado.

Contudo, ainda é necessário repensar a transposição do conceito e das problemáticas adjacentes de forma específica aos ambientes online (Caspary \& Manzenreiter, 2003, Amaral, 2007) bem como especificidades de produção de conteúdo criativo, emergentes a partir de seus perfis como performances de gosto (Liu, 2008), blogs, sites de redes sociais (Hodkinson, 2006, 2007) e plataformas de música online (Baym \& Ledbetter, 2008) ${ }^{12}$, entre outros.

Afinal é a partir do choque entre as contradições e complementariedades dos aspectos micro (que aqui denomino subculturais) e macro (da ordem de um contexto teórico-metodológico) da cibercultura que poderemos analisar com acuidade epistemológica o Zeitgeist tda cultura digital em suas facetas cotidianas, "pluriversas e intermináveis" ou mesmo segregadoras e histriônicas.

\section{Considerações finais: estilos de vida e regimes ciberculturais}

- Sim. Nós, às vezes, também conseguíamos orientar as pessoas para a direção certa. Mas o resultado, quase desde o começo, excedeu em muito qualquer coisa que qualquer um de nós havia esperado.

- Vocês presenciaram o nascimento de uma subcultura - diz Bigend. - Evoluindo exponencialmente (Gibson, 2004: 387, grifos da autora)

Rumo ao término desse breve ensaio indicamos algumas considerações acerca da importância das subculturas observando-as como um dos elementos fundadores da cibercultura, embora passível de questionamento em relação a esse termo em seu atual estágio.

A própria teorização e auto-reflexão das definições de cibercultura nos apresenta uma assemblage teóricaepistemológica na qual os computadores passam de inimigos de empregos, frios e despersonalizados nos anos 50, à "personalização" e geração de conteúdo pelos usuários na atual fase da Web, seja em perfis de sites de redes sociais, microblogs, tecnologias móveis etc nessa primeira década do século XXI que está prestes a findar.

Bruce Sterling convinced me a decade ago that bohemias were the dreamtime of industrial civilisations, that they are a function of the modern project. But if we are now in some postmodern state, are bohemias still valid? Can that still happen? I don't actually know. We maybe passed that. It doesn't mean that there will necessarily be an absence of the things we associate with bohemias, in fact it may mean that there' 11 be more of those things distributed more evenly through society.

It may not be possible in this sort of massively distributed marketing-based world in which we live for people to form those clubby bonds of old school bohemia with other people of like minds. It may just not be there. But it's not there in the respect that the people don't have the receptor sites in this society for that sort of bonding. It's just that we have changed in ways that we don't fully appreciate. (Gibson, 2008, Online) 
Essa transformação cultural em relação às TICs se deve muito ao amálgama entre os sistemas de pesquisa, as subculturas computacionais utópicas das primeiras redes, o imaginário da literatura de Ficção Científica, os primeiros usuários dos sistemas de informação online e os modos de vida contraculturais norte-americanos sessentistas (Turner, 2006).

Nesse percurso, observamos que os estilos de vida e os elos/laços podem ser efêmeros e descontinuados ou fortes e sedimentados de acordo com a multiplicidade e a dedicação em relação aos marcadores identitários online e offline, que, embora sejam distintos dos marcadores de gerações anteriores se reconfiguram em práticas sócio-culturais delimitadas pelos traços e rastros que vão sendo deixados nas redes digitais bem como na interação com os ambientes urbanos.

Conforme nos indicam pesquisas recentes, como a Digital Youth nos Estados Unidos (http:// digitalyouth.ischool.berkeley.edu/) e uma pesquisa realizada no contexto latino-americano do México (MartínBarbero et al, 2003) apontam, não para o ensimesmamento e para a perda de ligação com o mundo físico, mas sim para vivências e experiências de sociabilidade exploratórias e sensíveis tanto nos contextos da cultura digital como na cultura das "ruas".

Ainda que haja razões para esses temores, as pesquisas sobre os usos que os jovens fazem do computador traçam outro panorama. Como nos mostrou a investigação citada anteriormente, nem a dependência, nem o isolamento, nem a perda do sentido da realidade são a tendência mais visível. Em nossos países, a juventude que usa freqüentemente a Internet segue igualmente freqüentando a rua, curtindo festas nos fins de semana e preferindo a companhia ao isolamento. Há certa dependência, mas essa não é a única nem a mais forte e, claro, não é dessa que se morre, mas de outras.(MARTÍN-BARBERO, 2008: 22-23)

Talvez se pensarmos mais na "audiência invisível" mas mensurável e rastreável pelos mecanismos de busca e análises dos visitantes da Web - composta por grupos como Otakus, Steamers ${ }^{13}$, gamers, adeptos do software livre, seguidores de Barack Obama via serviços de postagem de micro-conteúdos como o Twitter ${ }^{14}$ e outros milhares de grupos sociais que nascem e morrem entre os cenários urbanos e as conexões tecnológicas, talvez tenhamos mais repertório e elementos empíricos para compreender e analisar os regimes e estilos de vida não construídos, mas amplificados pela cibercultura. Como nos propõe Canevacci (2005: 20), "é hora das ciências sociais também transitarem da subcultura ao sprawl 15 " wameCOS

\section{NOTAS}

* Conferência apresentada no II Simpósio ABCiber -
Associação Brasileira dos Pesquisadores em Cibercultura, realizado de 10 a 13 de novembro de 2008 na PUCSP, São Paulo.

1 Os relatórios da pesquisa de três anos, conduzida por uma equipe de 28 pesquisadores nos Estados Unidos está disponível em http:// digitalyouth.ischool.berkeley.edu/files/report/digitalyouth-WhitePaper.pdf

2 Otaku é uma palavra japonesa que originalmente refere-se a um tratamento respeitoso na segunda pessoa, como a sua família, o seu clã. No entanto, desde os anos 80 , o termo passou a designar uma gíria para os grupos de fãs que se envolvem de forma obsessiva em um hobby como colecionar animes, mangás, bonecos e outros artefatos de consumo relativos à cultura pop. Para uma compreensão mais específica do papel dos Otakus na cultura contemporânea ver, entre outros, Barral (2000), Amaral \& Duarte (2008), Duarte (2008) e Fernandes (2008), entre outros.

3 Essa tentativa de fundação de um futuro de ficçãocientífica, ou retro-futuro (Bukatman, 1993) que se alimenta dos dejetos passados, está no cerne das utopias da primeira fase e das primeiras definições de cibercultura, conforme nos indica Macek (2005).

4 Tradução da autora

5 Tradução da autora

6 Tradução da autora

7 Meramente para fins didáticos comparamos aqui o engajamento dos membros de uma subcultura com os participantes de um determinado fandom, haja vista as semelhanças nas maneiras de produção e distribuição do conteúdo online.

\section{Tradução da autora}

9 Tal problemática pode ser encontrada em autores como Hebdige (1979), Thronton (1996), Gelder \& Thornton (1997), Muggleton \& Weinzeirl (2004), Freire Filho(2007), entre outros.

10 Segundo o historiador Peter Burke (2003: 41-42), o contexto histórico original da noção de apropriação remonta à história do Ocidente desde a Antigüidade Clássica, mas têm suas origens mais próximas inspiradas na tradição cristã medieval em uma crítica às imitações dos modelos estrangeiros por parte de "teólogos agora reverenciados como Doutores da Igreja sobre os usos da cultura pagã que eram permitidos aos cristãos"cuja idéia era apropriação ou"espoliação". 
11 De herança sociológica, a noção de "multiplexidade de mídias" édesenvolvida por Haythornthawaite (2005) relacionando a questão numérica de ferramentas midiáticas ao fortalecimento dos laços sociais.

12 Interessante é observar a pluralidade de possibilidades metodológicas apresentadas nesse tipo de pesquisa, variando desde aspectos netnográficos, a análise de redes sociais, análises das materialidades dos objetos entre outras perspectivas em um trânsito interdisciplinar.

13 Os Steamers são como se auto-intitulam os fãs e adeptos da cultura steampunk, subgênero da ficção-científica que mistura elementos vitorianos (e das máquinas a vapor, daí o termo steam) com gadgets tecnológicos. De um gênero literário, o steampunk transmigrou em um amplo crescimento desde a chamada computação neovitoriana como produtos midiáticos como quadrinhos, filmes, moda, música, até produtos customizados como notebooks e computadores modificados materialmente para ficar com aspecto vitoriano. Para maiores detalhes ver Steampunk Magazine (norte-americana), disponível em http:// www.steampunkmagazine.com/pdfs/ SPM1-web.pdf e nos inúmeros conselhos stemapunk que se disseminam pelos estados brasileiros (São Paulo, Rio de Janeiro, Rio Grande do Sul, entre outros) em http://www.steampunk.com.br/

14 http://twitter.com

15 Referência à trilogia cyberpunk escrita por William Gibson, conhecida como a trilogia do Sprawl, iniciada com Neuromancer, seguida pelos livros Count Zero e de Mona Lisa Overdrive. É o "nome dado à megacidade composta pela junção entre todo o terreno urbano existente entre Boston e Atlanta (incluindo Nova York e Washington), nos Estados Unidos. Por isso também é conhecido pelo nome BAMA (Boston Atlanta Metropolitan Axis, ou seja, Eixo Metropolitando Boston-Atlanta)"(Glossário deNeuromancer, p. 311, 2008)

\section{REFERÊNCIAS}

AMARAL, Adriana. (2008). A potência do imaginário de Neuromancer nas origens da cibercultura. In: GIBSON, William. Neuromancer. Trad. Fábio Fernandes. São Paulo: Ed Aleph, 4a.ed, pp-305-308.

- (2007). Cybersubculturas e cybercenas. Explorações iniciais das práticas comunicacionais electro-goth na Internet. Revista FAMECOS, ed. 33, Dezembro, pp. 21-28. Disponível em <http://www.pucrs.br/fame$\cos / \mathrm{pos} />$

AMARAL, Adriana, DUARTE, Renata F.R. (2008) A subcultura cosplay no Orkut: comunicação e sociabilidade online e offline. In: BORELLI, Silvia H.S., FREIRE FI-
LHO, João (orgs). Culturas juvenis no século XXI. São Paulo: EDUC, pp. 269-288.

ANDERSON, Chris. (2006). A cauda longa. Do mercado de massa para o mercado de nicho. São Paulo: Ed. Campus.

BARRAL, Étienne (2000). Otaku - Os filhos do virtual. São Paulo: Ed. SENAC.

BARBROOK, Richard, CAMERON, Andy (2001). Californian Ideology. In: LUDLOW, Peter (ed). Crypto anarchy, cybestates and pirate utopias. Cambridge: MIT Press.

BAYM, Nancy, LEDBETTER, Andrew. (2008). Tunes that Bind? Predicting Friendship Strength in a Music-Based Social Network, Aoir, 2008.

BELL, Kennedy, KENNEDY, Barbara M. (ed) (2000). The cybercultures reader. New York, Routledge.

BENEDIKT, Michael (ed) (1994). Cyberspace: first steps. Boston: MIT Press, 6a.ed.

BROCKMAN, John. (1996). Encounters With the Cyber Elite. New York: Hardwired.

BUKATMAN, Scott (1993). Terminal identity. The virtual subject in post-modern science fiction. Durham: Duke University Press.

BURKE,Peter.(2003).Hibridismo cultural.São Leopoldo: Unisinos.

CASPARY, Costa, MANZENREITER, Wolfram (2003). From subculture to cybersubculture? The Japanese Noise alliance and the Internet. In: GOTTLIEB, Nanette, McLELLAND, Mark (ed). Japanese cybercultures. New York: Routledge, pp.60-74.

CANEVACCI, Massimo. (2005). Culturas eXtremas. Mutações juvenis nos corpos das metrópoles. Rio de Janeiro: DP\&A.

DERY, Mark. (1997). Escape velocity.Cyberculture at the end of the century. New York: Grove Press, 1a.ed.

DIXON, Joan B., CASSIDY, Eric J. (1998) Virtual Futures. New York, Rouledge.

DONATH, Judith.S., (1999), Identity and Deception in the Virtual Community. In: SMITH, M.A.,

KOLLOCK, P. (eds.) (1999), Communities in Cyberspace. London: Routledge.

DUARTE, Renata F.R. (2008) Práticas comunicacionaise sociais dos cosplayers no Brasil: uma análise dos processos online e offline através do Orkut. Dissertação(Mestrado em Comunicaçãoe Linguagens). Universidade Tuiuti do Paraná, Curitiba. 
FELINTO, Erick (2007). Sem mapas para esses territórios: a cibercultura como campo do conhecimento. In: FREIRE FILHO, João e HERSCHMANN, Micael (orgs). Novos rumos da cultura da mídia. Indústrias, produtos, audiências. Rio de Janeiro: Mauad.

FERNANDES, Fábio. (2008). A Construção do imaginário ciborgue. O pós-humano na ficção científica, de Frankenstein ao século XXI.Tese (Doutoradoem ComunicaçãoeSemiótica).Pontifícia Universidade Católica de São Paulo, São Paulo.

FREIRE FILHO, João (2007). Reinvenções da resistência juvenil. Os estudos culturais e as micropolíticas do cotidiano. Rio de Janeiro: Mauad.

GELDER, Ken, THORNTON, Sarah. (ed.) (1997). The subcultures reader. New York: Routledge.

GIBSON, William. William Gibson Interview by Ulrich Gutmair. (2008). 04/09/2008. Disponível em <http:// voidmanufacturing.wordpress.com/2008/10/01/ william-gibson-interview/> Acesso em 05/09/2008.

GIBSON, William.(2004). Reconhecimento de padrões. (2004). Trad. Fábio Fernandes. São Paulo: Ed. Aleph.

GOFFMAN, Ken, JOY, Dan. (2004). Counterculture through the ages. From Abraham to acid house. New York: Villard.

HAYTHORNTHWAITE, Caroline. (2005). Social networks and Internet connectivity effects. Information, Communication, \& Society, 8 (2), 125-147.

HEBDIGE, Dick (1979). Subculture: the meaning of style. London: Methuen.

HODKINSON, Paul (2007). Interactive Online Journals and Individualisation. New Media and Society, 9 (4). Disponível em <http://www.paulhodkinson.co.uk/publications/ hodkinsonnmsarticle.pdf> Acesso em 05/10/08.

(2006). Subcultural Blogging: Online Journals and Group Involvement Among UK Goths'. In: BRUNS, Axl, JACOBS, Y(eds.), Uses of Blogs, Peter Lang.

ITO, Mizuko et al (2008). Living and learning with new media: Summary of Findings from the Digital Youth Project. The John D. and Catherine T. MacArthur Foundation Reports on Digital Media and Learning. Disponível em http:// digitalyouth.ischool.berkeley.edu/files/report/digitalyouth-WhitePaper.pdf Acesso em 22/11/08.

JENKINS, Henry. (2006). Fans, bloggers and gamers. Exploring participatory culture. NewYork: New York University Press.

JENKINS, Henry, TULLOCH, John (1995). Science Fiction
Audiences: Doctor Who, Star Trek and Their Followers. London: Routledge, Chapman and Hall.

LEMOS, André. (2002) Cibercultura. Tecnologia e vida social na cultura contemporânea. Porto Alegre: Ed. Sulina, 1aed.

LEVY, Steven. (1984). Hackers. Heroes of the computer revolution. New York: Anchor Press.

LIU, Hugo. (2007). Social Network profiles as taste performances. Journal of Computer-Mediated Communication, 13(1), article 13. Disponível em <http:// jcmc.indiana.edu/vol13/issue1/liu.html > Acesso em 10/09/2008.

MARTÍN-BARBERO, Jesús. (2008). A mudança na percepção da juventude: sociabilidades, tecnicidades e subjetividades entre os jovens. In: BORELLI, Silvia H.S., FREIRE FILHO, João.(orgs). Culturas juvenis no século XXI. São Paulo: EDUC.MACEK, Jakub. (2005). Defining cyberculture. Disponível em <http:// macek.czechian.net/defining_cyberculture.htm>

MARTÍN-BARBERO, Jesús, AMÉZQUITA, Irma, MEDINA, Daniel, ARÉCHIGA, Yadel (2003). Usos adolescentes de internet. Cibernautase cibercreadores. Guadalajara, Departamento de Estudios Socioculturales del ITESO.

MUGGLETON, David, WEINZIERL, Rupert (ed.) (2004). The post-subcultures reader. New York: Berg.

RHEINGOLD, Howard (1993). The virtual Community. Cambridge: MIT Press.

RECUERO, Raquel (2008). Cibercultura x Cultura de massa. Depoimento gravado no documentário Cibercultura. In: BUCHAUL, Luiza. Cibercultura. Trabalho de Conclusão de Curso de Luiza Buchaul, Rio de Janeiro.

ROSS, Seamus (2001). Cyberculture, cultural assetmanagement, and ethnohistory. In: Preserving the present for the future. Proceedings of Conferences on Strategies for the Internet Copenhagen 2001. Disponível <http://www.deflink.dk/eng/arkiv/ dokumenter2.asp?id=695> em Acesso em 05/10/2008.

RÜDIGER, Francisco. (2008). Cibercultura e pós-humanismo. Porto Alegre: EDIPUCRS.

THORNTON, Sarah (1996). Club cultures. Music, media and subcultural capital. Connecticut:Wesleyan University Press.

TOFTS, Darren. (1998). Memory trade: a prehistory of cyberculture. Australia: Interface.

TURNER,Fred.(2006). From Counterculture to cyberculture. Stewart Brand, the Whole Earth Network and the Rise of the Digital Utopianism. Chicago:TheUniversity of Chicago Press. 